\title{
Listing-Oriented Logistics Service Strategy: A New Choice for Large Transactional Online Shopping Websites
}

\author{
Dongli Miao1, Jianjun Lu1 ${ }^{*}$, Guangying Xie ${ }^{2}$ \\ ${ }^{1}$ College of Economics and Management, China Agricultural University, Beijing, China \\ ${ }^{2}$ Business School, Renmin University of China, Beijing, China \\ Email: MDLmiaodongli@126.com, *1jjun@cau.edu.cn,xgynefu@126.com
}

How to cite this paper: Miao, D.L., Lu, J.J. and Xie, G.Y. (2017) Listing-Oriented Logistics Service Strategy: A New Choice for Large Transactional Online Shopping Websites. Journal of Service Science and Management, 10, 1-12.

https://doi.org/10.4236/jssm.2017.101001

Received: December 2, 2016

Accepted: February 6, 2017

Published: February 9, 2017

Copyright (๑) 2017 by authors and Scientific Research Publishing Inc. This work is licensed under the Creative Commons Attribution International License (CC BY 4.0).

http://creativecommons.org/licenses/by/4.0/

\begin{abstract}
Behind the fast development of online shopping market in China, there are the risk of bankruptcy and development dilemma caused by huge loss. This paper suggests that they should take improving logistics service quality as short-term goal, and appearing on the stock market as middle-term goal. By transferring a part of capital from pricing strategy and promoting strategy to logistics department, the logistics service quality could be greatly improved though with little profit or even loss. This could attract customers, enlarge sales and market shares, and finally attracting venture capital fund and realizing listing strategy successfully. This strategy is based on the principle of systematic optimization and called listing oriented logistics service strategy. Finally, this paper analyzes the acceptance of this listing oriented logistics service strategy with TAM model for large-sized transactional shopping websites, it would be increased with the pressure of fierce market competition as well as increased customer needs.
\end{abstract}

\section{Keywords}

Large Transactional Online Shopping Websites, Logistics Service, Technology Acceptance Model, Marketing Strategy

\section{Introduction}

Online Shopping refers to the transactions of goods and services through Internet, including Business to Business (B2B), Business to Consumer (B2C) and Consumer to Consumer (C2C) and Government to Business (G2B). According to the definition China Internet Network Information Center (CINIC) used when making the statistics, this article would use the narrow definition of online 
shopping, which only covers B2C and C2C online shopping [1]. In 2015, the total amount of China's online shopping market transactions reached 3.88 trillion RMB, which increased by $33.3 \%$ compared with 2014 . Besides, the proportion of the total online shopping market transactions accounting for retail sales of consumer goods increased to $12.9 \%$. According to China Internet Network Information Center, the scale of China's online shopping market has been keeping a high growth rate since 2010, increased by nearly 7 times in the last 6 years [2]. The online shopping market turnover and growth rate data from 2010 to 2015 are shown in Figure 1.

The rapid growth of online shopping market transaction is largely caused by the quantity of China cyber citizens' steady increase. In the end of December 2015, China's online shopping users reached 413 million. In addition, the proportion of Internet users who use online shopping increased to $48.9 \%$ [2]. Figure 2 shows the number of online shopping users and their proportion in the overall internet users from 2010 to 2015 [3].

Although the large transactional online shopping websites' own strength is

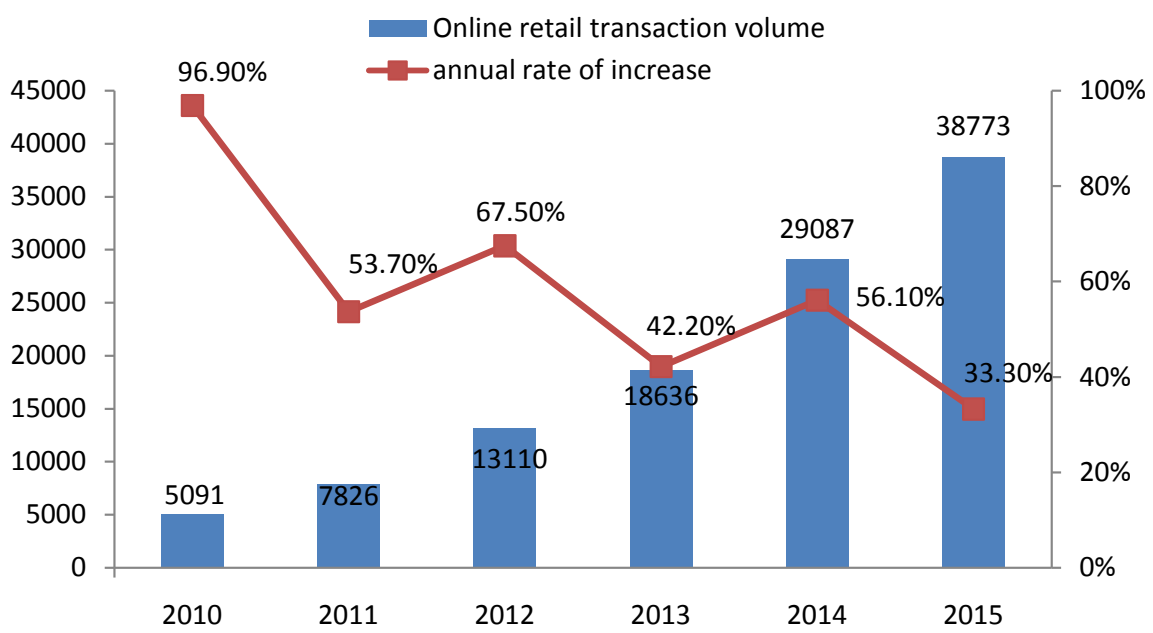

Figure 1. Online shopping market turnover and growth rate from 2010 to 2015.

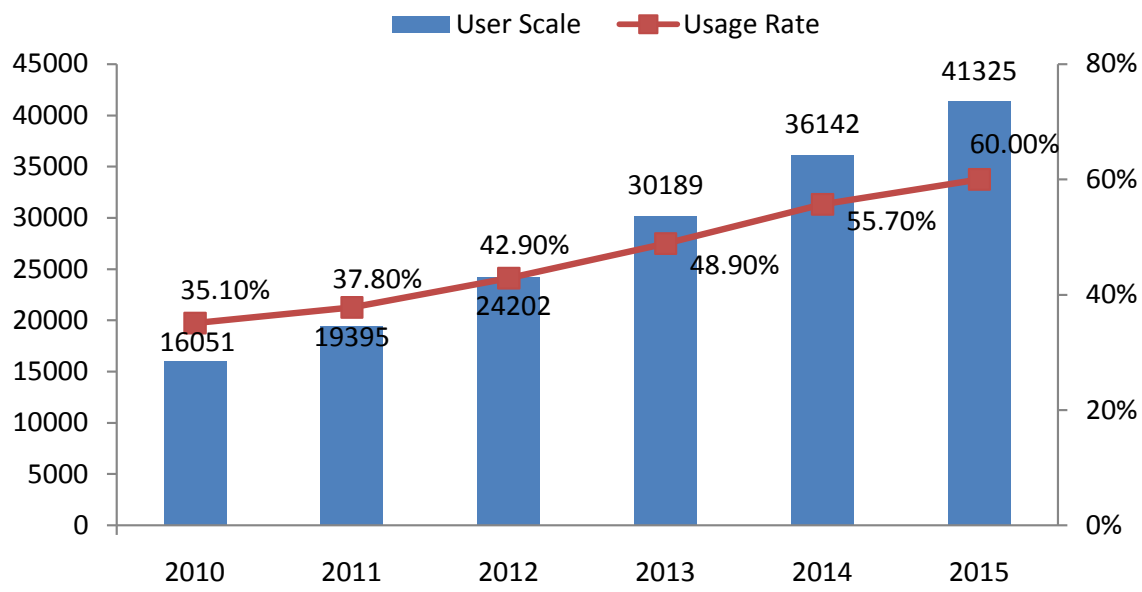

Figure 2. The number of Online Shopping users and their proportion in the overall internet users. 
relatively strong, more investment, and has good development opportunities, but due to the development of the Internet, the emergence of a large number of transaction shopping sites (including large, medium and small shopping sites), plus other new entrants as well as from suppliers and customers and the threat of alternatives, short-term loss or micro-profit has become a common phenomenon. Based on the analysis of existing cases, this paper puts forward the strategy of logistics service based on listing and analyzes the feasibility of this strategy by using technology acceptance model.

\section{The Development Dilemma of Large Transactional Online Shopping Websites}

The rapid development of online shopping improved the quantity of online shopping websites. According to China Internet Network Center's official statistics, as early as the end of June 2010, there were already about 20,700 electronic business websites which have a certain scale, including 12,500 enterprises with the form of $\mathrm{B} 2 \mathrm{C}, \mathrm{C} 2 \mathrm{C}$ and other non-mainstream business models Network operators has reached 77 million, including 65 million of individuals and 12 million of business firms. The expansion of Online shopping infrastructure indicates that there is sufficient capability to keep a fast growth in turnover, which makes this market more and more competitive.

Online shopping sites can be divided into transactional shopping sites and platform shopping sites. The former sells goods directly, while the latter provides a third-party sales platform for other enterprises. We divided the size of the shopping site by the size of their company. According to the Ministry of Industry and Information Technology, the National Bureau of Statistics, the National Development and Reform Commission, Ministry of Finance "on the issuance of SME zoning standards notice", with reference to employees, operating income, total assets and other indicators or alternative indicators, we divided companies into large, medium, small, micro-four types. This article targets at large-scale transactional shopping sites, some representatives of them are are Jingdong and Yihaodian. As the online shopping market competition is becoming increasingly fierce, large-sized shopping site is also facing a severe problem of survive and development. Shanghai-based B2C website Dahuozhan declared to be closed due to the loss of investment confidence in the shareholders in September 2011. Looking back on those transactional shopping sites which have been successfully listed, Mecox Lane took eight years to make a profit, while Dangdang net spent nine years in turning around. Therefore, profit may not be their first pursue at this time, at least could not be realized in a short time. They have to seek for other solutions for defeating competitors and gain development. Figure 3 shows the net profit of Dangdang from 2011 to the third quarter of 2015, data are sourced from the Dangdang annual report.

We can see that from Figure 3, over the past five years, in addition to a few quarters of micro-profit, the Dangdang are basically at a loss. Since the third quarter of 2011, there has been a large loss, and the loss is far more than the total 


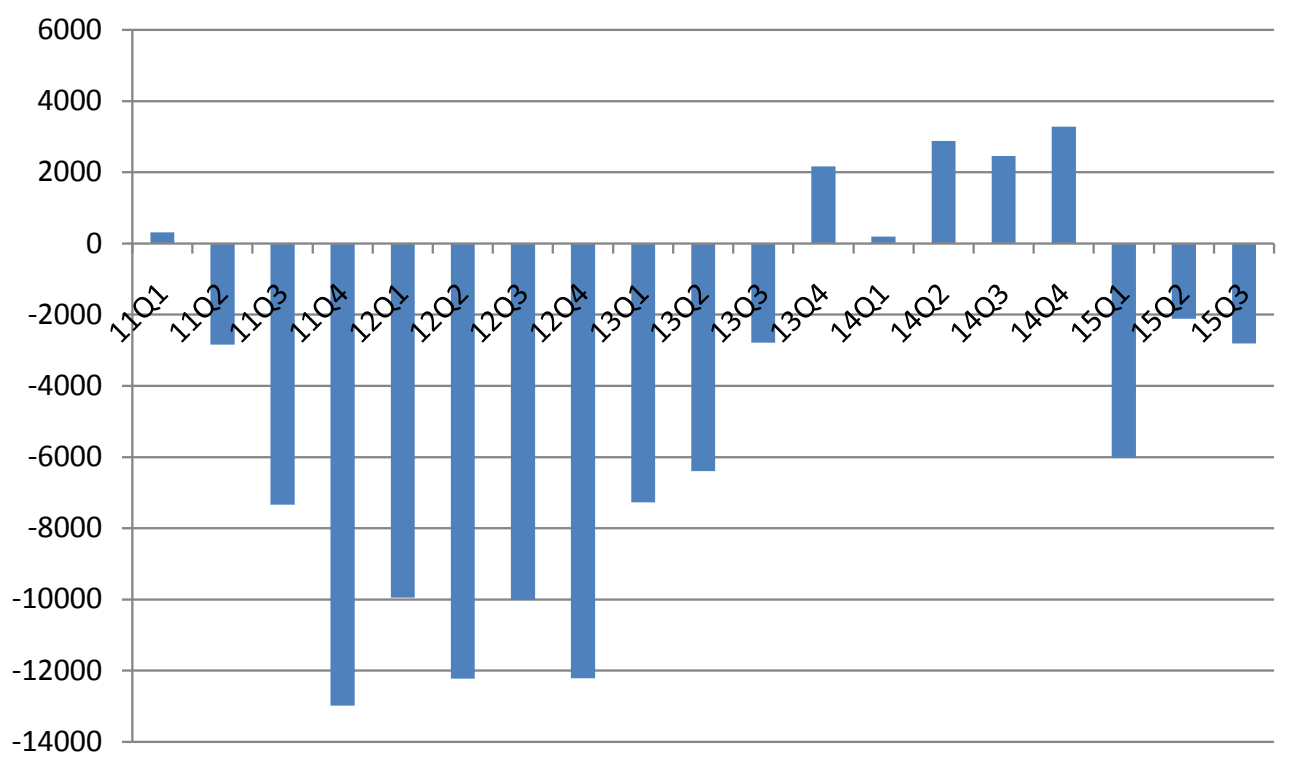

Figure 3. Dangdang 2011-2015 profit chart (Units: ten thousand RMB).

previous profit. Years of losses like this is not an specific phenomenon in Dangdang. Figure 4 shows the Mecox Lane's net profit from 2011 to the second quarter of 2015, data are collected from Mecox Lane annual report.

Figure 4 shows that there is a similar situation in Mecox lane, who has also been at a loss since 2011 and the loss rate was significantly higher than the profit.

For large transactional online shopping websites, continuous losses would increase their risk of bankruptcy and discourage their development. Traditional price wars and promotion wars have put them in trouble, thus how to get rid of this dilemma is a urgent problem they face.

\section{Large-Sized Online Shopping Websites: What Should They Do Next?}

Although large transaction shopping site is powerful and has better opportunities for development, loss or micro earnings will continue to be a universal phenomenon in the short term because of the intense competition from existing platform-based shopping sites, other small and medium sized transactional online shopping websites and the threat of new entrants from the supply chain, customers and alternatives. This part will focus on the necessity of listing oriented strategy and its requirements, and listing of their own requirements, putting forward a listing oriented strategy of logistics services to deal with the risk of failure and development plight.

1) The necessity of being listed for large transaction online shopping websites

Fierce market competition makes almost all major online shopping sites have to sacrifice profit for the turnover of trade and the number of customers, resulting in a variety of price wars and sales promotion battles. Price is the main factor affecting consumers who choose online shopping, but the transparentizing of information and the appearance of price-comparing tools greatly weakened the 


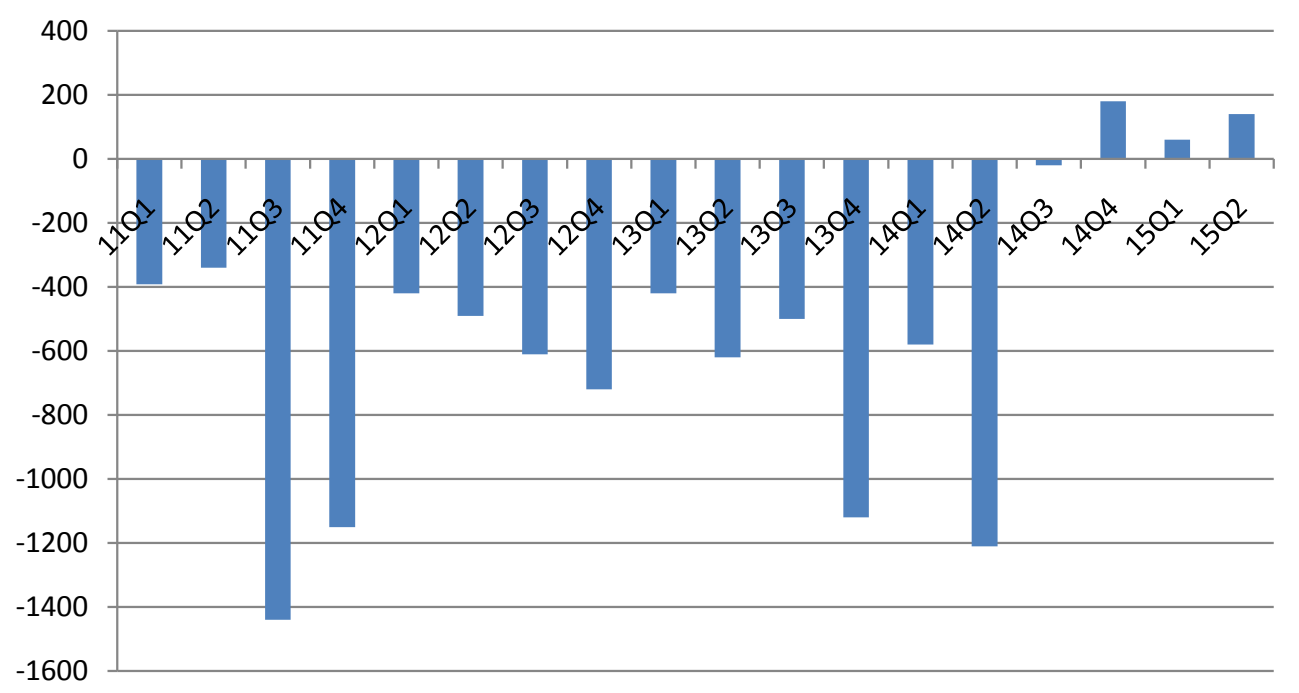

Figure 4. Mecox lane 2011-2015’s net profit chart (Units: ten thousand dollars).

role of price in competition, which also leads to the low profit or even at a loss of the large transactional online shopping sites [4].

Since large transactional online shopping sites have been trapped in the dilemma of at a loss or low profit, it is difficult to achieve the goal of huge profit in the short time. The reason and motivation that lead to large transactional online shopping sites' surviving are a key issue that we should carefully analyze. Currently the mainstream feature of Chinese electronic market is free. Microsoft was aware of this, so it tolerated the existence of a large number of domestic pirated $\mathrm{CD}$ of their system, which quickly occupied the domestic market of China. Alibaba Group's Taobao has been committed to provide free trading platform services for buyers and sellers, which attracted a large number of customers and promoted the rapid development of Chinese e-commerce. After successfully defeating the rivals, gaining a large number of loyal customers and occupying the leading position in the market, these companies started to consider the charging policy. For example, the Microsoft began to strengthen copyright control. And on the basis of Taobao, Alibaba opened Tianmao Mall. Consequently, we can conclude that the current trading loss or little profit of the major large transactional shopping sites is not terrible. What is important is the quantity of customers and market share.

For example, on May 22, 2014, Jingdong group (NASDAQ stock code: JD) officially listed on the NASDAQ, raising a total of $\$ 1.78$ billion. Bank of America Merrill Lynch and UBS Securities acted as underwriters of the IPO, and Price Water House Coopers acted as comptroller. Prospectus showed that the net revenue of Jingdong is 21.129 billion yuan in 2011 and 41.381 billion yuan in 2012 , and the operating loss is 1.284 billion yuan in 2011 , and 1.723 billion yuan in 2012, with the net loss of 1.284 billion yuan in 2011 and 1.729 billion yuan in 2012 .For the first three quarters of 2013, the net revenue was 49.216 billion yuan compared to last year's 28.807 billion yuan over the same period; profiting with 60 million yuan, which is the first time to make profit, but it was a loss of 1.424 
billion yuan at the same period last year.

However, sustained losses is also a big hit for large transactional online shopping sites. Although large turnover and cash flow can temporarily maintain the normal operation, enterprises are still facing the risks caused by losses, thus the support of venture capital is the most fundamental and basic thing they should deal with. Jingdong have completed five rounds of financing during 2007-2013, raising a total of over $\$ 2$ billion. In 2014, JD listed in New York, raising \$1.78 billion.

For venture investors, short-term losses are acceptable, as the long-term value of the invested assets is more important. The most significant opportunity for the risk investors is to be listed and gaining investment revenues from public offers and IPO premium.

2) the NASDAQ listing requirements and its implications for large transactional online shopping websites.

NASDAQ provides alternative listing criteria for non-US companies, option one: net tangible assets of no less than $\$ 4,000,000$; recent year (or two years in the last three years) has a pre-tax profit of not less than $\$ 700,000$; after-tax profit of not less than $\$ 400,000$, the outstanding market capitalization is not less than three million dollars; public shareholders holding more than 100 million shares, or more than 50 million shares and the average daily trading volume of more than 2000 shares, but the US shareholders of not less than 400 people and the stock price of not less than 5 dollars. Option two: net tangible assets of not less than 12 million US dollars; the public shareholding value of not less than 15 million US dollars; holding not less than 100 million shares; the US shareholders of not less than 400 people; no pre-tax profit requirements; the company should have a business record of not less than three years and a share price of not less than $\$ 3$.

From this point of view, the NASDAQ listing has a higher requirement for net tangible assets but lower net profit requirements. After scale expansion, the Chinese large transactional online shopping websites are easy to realize overseas listing. On the other hand, if overseas IPO wanted to get the IPO premium, large transactional online shopping websites need to provide stock subscribers with a good expectation about the company's development and value. In addition to the profit situation, the turnover, customer scale and market share are main evaluation indexes. If a large transactional shopping site wanted to enhance its listing capabilities, they would better to improve their scale and turnover, and attracting and maintaining a large number of loyal customers at the same time.

3) Large transactional online shopping websites: How to do?

System is an organic unity consisted of interconnected individuals. From a systematic perspective, the attitude of customer towards logistics service has a direct connection with the evaluation of the online shopping site. Online shopping and the actual logistics and distribution services constitute the goods service system of large transactional online shopping websites [5]. According to China Internet Network Information Center's statistics in 2015, when online 
shopping users were purchasing goods, $47.3 \%$ of consumers believed that delivery speed is the main consideration, while $43.3 \%$ of consumers believe that the credibility of the courier company is the main decision factor [2]. From the current competition point of view, large transactional online shopping websites are focusing on price wars and promotional campaigns, lacking of investment in logistics services. Although Jingdong Mall's 211-time limit logistics strategy has achieved great success, it only covered a limited area and commodity range. Moreover, the delivery times can be further compressed.

In order to improve logistics service quality of online shopping, companies need to invest in a lot of infrastructure which would cost much. If only considering from the perspective of the logistics industry's profits, the amount of inputs would be significantly limited [6]. Whether in self-logistics sector of some large transactional online shopping websites, or in the third-party logistics enterprises, efforts to improve the quality of logistics services from the perspective of profit are very difficult to obtain a clear advantage in the competition with other competitors. Currently large transactional online shopping websites are mainly focus on price strategy and sales promotion [7]. Although they reluctantly maintained the customer, they are facing the impasse of micro-profit or even a loss. Based on the perspective of system [8], goods and logistics services formed a commodity system of large transactional online shopping website. Now that the current price war and sales promotion war could not provide sufficient core competitiveness for large transactions shopping site, some of the funds which are used to fight a price war and a promotion war could be transferred to build good logistics services. By increasing the logistics services investment and implementing listed-oriented logistics services strategy to attract and keep customers may help them get rid of the risk of being shut down. Although this strategy may not enable these companies to achieve large-scale profits in the short term, it is a blue ocean strategy worth considering and trying [9]. Listedoriented logistics services strategy is no longer like the traditional strategy that aimed at the lowest logistics costs, but stresses the experiences and satisfaction of customers. By offering a very unique kind of logistics services to customers to create a shock from the heart and to exceed customers' expectations to get word of mouth marketing effect, the listed-oriented logistics service marketing strategy would finally attract and maintain a large number of loyal customers and achieve the huge growth in sales and allow large transactional online shopping websites to get more venture capital funds and being successfully listed.

Through the above analyses, since the large transactional online shopping sites are impossible to achieve a massive and sustained profitability in the short term, the losses would continue for a while. To survive, large transactional online shopping websites must get support from venture capital funds. To develop, one of the best choice for large transactional online shopping sites is coming into the public market. Thus getting into the public market and seeking for support from venture capital funds would be two most important goals for large transactional online shopping websites currently. Listed oriented has raised some re- 
quirements for online shopping websites in the net profit of large transactions, asset size, business scale and business life. Large transactions shopping sites need to select an appropriate opportunity to meet these conditions and make shareholders to recover the investment costs and generate revenue by the premium through IPO. To meet the listing requirements, the customer scale and business scale are two important indicators. Customer size is directly related to the market share, while for the business scale, enterprise asset size and profit are closely related. The two indicators are also the indicators that venture capital funds used to evaluate large transactional online shopping websites. In order to increase the numbers of the customers and promote customers to purchase, large transactional online shopping websites could improve the quality of service of them, increase the types of goods, cut down the price to promote sales etc. But these strategies have been widely adopted, and the effect is not obvious, at least could not save them from the above dilemma. On the contrary, it caused large transactional online shopping websites to be trapped into a dilemma of price war, whose losses become more and more due to the wrong competitive strategy. This paper argues that the implementation differentiation strategy in logistics service could provide new ideas for large transactional online shopping websites to attract customers and facilitate customers to purchase. Their excellent logistics services can become a new marketing tool for increasing sales. When implementing the listed-oriented logistics service marketing strategy, according to the system optimization theory, large transactional online shopping websites transferred some of the funds used in price war into improving the quality of logistics service to achieve a customer shock here. This strategy ignores the profits of the logistics sector with the consideration of improving the quality of logistics services and attracting customers and promoting their purchase.

\section{Would the Listed-Oriented Logistics Service Marketing Strategy Be Adopted?}

Earlier we analyzed the bankrupt risk and developing difficulties that large transactional online shopping websites are facing. Considering the opportunities and threats in the external environment together with the strengths and weaknesses of large transactional online shopping websites, we suggested a strategy of listed-oriented logistics services marketing and elaborated the implementation steps of that strategy. However, would the large transactional online shopping websites accept it? We would discuss about it in the following part.

1) Introduction of the technology acceptance model

The technology acceptance model is a model proposed by Davis in 1989 when he used rational behavior theory to study user acceptance of information systems. The model was originally developed to interpret and analyze the determinants that are widely accepted by computers [10]. Technology acceptance model's core perspective is that there are two main factors that affect people's acceptance of things: the first is the perceived usefulness, which reflects the extent of improvement of job performance of an individual who consider the use of a spe- 
cific system. The second is the perceived ease of use, which reflects the ease of use of an individual think of a system.

The theoretical basis for the technology acceptance model is the theory of reasoned action and the theory of planned behavior [11] [12]. The model assumes that people determine the acceptance of something by behavioral intention, while the behavioral intention is determined by attitude towards using and perceived usefulness. Among that, attitude towards using is determined by perceived ease of use and perceived usefulness, perceived usefulness is determined by perceived ease of use and external environment variables, and perceived ease of use is determined by external environment variables. External environment variables include features of system design, user characteristics, task characteristics, policies, organizational structure and other factors. The technology acceptance model includes internal belief, attitude, intention, and various individual differences, environmental constraints, controllable disturbances. The external environment variables establish a link between the various factors present in the technology acceptance model.

Attitude of use refers to the subjectively positive or negative feelings of individual when they use the system. Behavioral intention is the degree of individual accomplishing a specific behavior. The model considered that the acceptance of a user is mainly determined by the individual user behavior intention. Use behavioral intention is determined by the use of attitude and perception of the usefulness $(B I=A+U$. Use of attitude is determined by the perceived usefulness and perceived ease of decision $(\mathrm{A}=\mathrm{U}+\mathrm{EOU})$. Perceived usefulness is determined by the external environment variables and perceived ease $(\mathrm{U}=\mathrm{EOU}+$ External Variables), perceived ease of use is determined by external variables $(\mathrm{EOU}=$ External Variables). Some external environment variables are measurable factors, such as training time, user manuals and other design features.

2) Applicability of Listed-oriented logistics service marketing strategy for large transactional online shopping websites based on TAM

For large transactional online shopping websites, Listing-oriented logistics services strategy is a new marketing strategy. The improvement of logistics service quality under the guidance of this strategy is fundamentally different from the traditional improvement of logistics service quality. The reason is that the listed logistics service strategy is the strategy considered from the perspective of the whole system. Logistics service as a part of the system as a whole does not require profits, or even a certain degree of loss of operations in order to obtain a substantial improvement in the quality of logistics services, and ultimately attracts customers and expands the scale of turnover.

Usually large transactional online shopping websites have already had a large customer size and turnover volume as well as a good reputation. An inevitable risk of implementation the listed-oriented logistics services strategy is the substantial increase of cost in logistics services improvement. For enterprises, the purposes of existence is to make profit. And if they want to make profit, an important part of operational management is to reduce costs. However, the listed- 
oriented logistics service strategy is different from the above by increasing logistics costs to improve the quality of logistics services, whose acceptability must be carefully analyzed and assessed.

According to the technology acceptance model, whether the large transactional online shopping websites would take this listed-oriented logistics service strategy in practice may be directly affected by their behavioral intentions. The behavior intention of the website is directly influenced by the acceptance attitude of the website to the listed-oriented logistics service strategy and the perceived usefulness of the strategy. The acceptance of this strategy is also affected by perceived usefulness and perceived ease of use of the strategy. Among them, perceived usefulness is influenced by perceived ease of use and external environment variables, and perceived ease of use is directly affected by external environment variables.

This means, fundamentally, whether the large transactional online shopping websites would accept and implement this strategy or not would be affected by the external environment variables. External environment variables not only include economic and social environment, but also cover some of its own resource and capability factors. From a macroeconomic and social environment point of view, the stable and rapid development of China's economy, the continuous expansion of the scale of the online shopping market and the continuous development of the logistics industry has facilitated the implementation of this listing-oriented logistics service strategy. The good environment also improves the perceived ease of use of a listed-oriented logistics service strategy. From the perspective of market competition, large transactional online shopping websites are facing fierce competition from other major platform-based online shopping websites as well as a number of small transactional online shopping websites. There are still a number of new entrants and potential entrants. Under the circumstances of transparency of information, gradual disappearance of the advantage of traditional price war and the improvement of consumer logistics service standards, the perceived usefulness of this strategy to the firms is also increasing.

There are also some negative factors which would influence large transactional online shopping websites' perceived usefulness and perceived ease of use in the external environment. While the environment variables promote perceived usefulness and perceived ease of continuously. First, the listed-oriented logistics services strategy's implementation process would cost a lot. Although these investment increased the quality of logistics services, whether high-quality logistics services can really bring a large number of customers and turnover is still to be observed. There is no precedent on the market, and there is no agency who conducted this professional survey. After a Large amount of investment in the improvement of logistics services, there are still some uncertainties in their avenues and attraction to customers. Besides, the usefulness of perception also needs to be appraised in practice. On the other hand, for large transactional online shopping websites, listed-oriented logistics service strategy is a strategy- 
oriented innovation, and other companies had not yet implemented such strategies in the market. There is no precedent to follow, thus it is very difficult to implement, and therefore the perceived usability is weak relatively. Even if the large transactional online shopping website have already established their logistics and distribution system, such as Jingdong, Dangdang, when implementing listing-oriented logistics services strategy they would still face the problem of specific logistics service quality improvement and measurement standards, as well as a rational analysis of the magnitude of the improvements and the gains achieved. These problems will reduce perceived ease of use of this strategy. If the large transactional online shopping website have not established their distribution system, then the implementation of this strategy would probably need to select one or several third-party logistics companies to establish strategic alliances, and implement customized logistics services. It not only refers to the logistics service quality standards and measurement issues, but also involves the selection and formation of strategic alliances and third-party logistics companies, which would result in a lower perceived ease of use.

Although there is some uncertainty in terms of perceived usefulness and perceived ease of use for large transactional online shopping websites to conduct this strategy, the development of economy and market competition create convenient conditions for perceived ease of use. In addition, the increasing demand about logistic service and the hard situation the large transactional online shopping websites are facing, as well as the need of differentiation marketing strategy will improve the perceived usefulness. China's online shopping market is in a stage of rapid development, fierce rivalry and struggling to make profits would last for a long time. Listed-oriented logistics service strategy is the most momentous way to improve the ability of being listed and attracting venture capital. The acceptance of this strategy would be increased continuously with the development of the market.

\section{Conclusions}

With the continuous development of China's online shopping market, the market volume is expanding, and the competition is becoming more and more fierce. Although the large transactional online shopping websites' turnover is high, it is encountering a dilemma of low profit or even loss. Listing-oriented logistics services strategy offers an innovative development method for large transactional online shopping websites. That is, through the implementation of differentiated listing-oriented marketing strategy to attract customers and increase the scale of turnover and market share, they would finally obtain the support of venture capital and appear in the public market successfully and retrieve investment by socializing the asset. With the support of venture capital funds, large transactional online shopping websites do not have to worry too much about the loss and being closed down due to lack of funds. Appearing on the market also makes each investor retrieve investment to make a profit. Enterprises could also obtain more convenient financing channels and better platform for develop- 
ment. Therefore, the risk of bankruptcy and their development predicament could be both settled.

Finally, this paper uses the technology acceptance model, from the perspective of perceived usefulness and perceived ease of use, to argue that the listed-oriented logistics service strategy would be gradually accepted by large transactional online shopping websites.

\section{References}

[1] China Internet Network Information Center (2012) China Online Shopping Market Research Report.

[2] China Internet Network Information Center (2015) China Online Shopping Market Research Report.

[3] China Internet Network Information Center (2013) China Online Shopping Market Research Report.

[4] Lai, M., Zhao, K. and Han, S. (2010) Needs and Present Condition of Online Scholarly Communication Service in China. International Conference on Management and Service Science, Wuhan, 24-26 August 2010, 1-7.

[5] Couceiro, M. and Marichal, J.L. (2007) Research on Evaluation Index System of Logistics Enterprise's Service Quality. Logistics Technology, 161, 694-707.

[6] Yuan, X. and Grant, D.B. (2006) Developing a Framework for Measuring Physical Distribution Service Quality of Multi-Channel and “Pure Player” Internet Retailers. International Journal of Retail \& Distribution Management, 34, 278-289. https://doi.org/10.1108/09590550610660233

[7] Weisstein, F.L., Kukar-Kinney, M. and Monroe, M.B. (2016) Determinants of Consumers' Response to Pay-What-You-Want Pricing Strategy on the Internet. Journal of Business Research, 69, 4313-4320. https://doi.org/10.1016/j.jbusres.2016.04.005

[8] Venkatesh, V. and Davis, F.D. (2000) A Theoretical Extension of the Technology Acceptance Model: Four Longitudinal Field Studies. Management Science, 46, 186204. https://doi.org/10.1287/mnsc.46.2.186.11926

[9] Ottosson, M. and Kindstorm, D. (2016) Exploring Proactive Niche Market Strategies in the Steel Industry: Activities and Implications. Industrial Marketing Management, 55, 119-130. https://doi.org/10.1016/j.indmarman.2015.08.003

[10] Davis, F. (1989) Perceived Usefulness, Perceived Ease of Use, and User Acceptance of Information Technology. MIS Quarterly, 13, 319-341. https://doi.org/10.2307/249008

[11] Mishra, D., Akman, I. and Mishra, A. (2014) Theory of Reasoned Action Application for Green Information Technology Acceptance. Computers in Human Behavior, 36, 29-40. https://doi.org/10.1016/j.chb.2014.03.030

[12] Saeri, A.K., Ogilvie, C. and La Macchia, S.T. (2014) Predicting Facebook Users' Online Privacy Protection: Risk, Trust, Norm Focus Theory, and the Theory of Planned Behavior. Journal of Social Psychology, 154, 352-369.

https://doi.org/10.1080/00224545.2014.914881 
Submit or recommend next manuscript to SCIRP and we will provide best service for you:

Accepting pre-submission inquiries through Email, Facebook, LinkedIn, Twitter, etc. A wide selection of journals (inclusive of 9 subjects, more than 200 journals)

Providing 24-hour high-quality service

User-friendly online submission system

Fair and swift peer-review system

Efficient typesetting and proofreading procedure

Display of the result of downloads and visits, as well as the number of cited articles Maximum dissemination of your research work

Submit your manuscript at: http://papersubmission.scirp.org/

Or contact jssm@scirp.org 